\title{
The Difference of Acetabular Cup Orientation Between Two Surgical Sides After Primary Total Hip Arthroplasty by Right-handed Surgeons
}

\section{Ao Xiong}

Peking University Shenzhen Hospital

su liu

Peking University Shenzhen Hospital

Guoqing Li

Peking University Shenzhen Hospital

Jian Weng

Peking University Shenzhen Hospital

Deli Wang

Peking University Shenzhen Hospital

Hui Zeng ( $\square$ zenghui_36@163.com )

Peaking University Shenzhen Hospital https://orcid.org/0000-0001-6966-0769

\section{Research article}

Keywords: Total hip arthroplasty, Handedness, Surgery side, Anteversion angle, Inclination angle, Safe zone

Posted Date: February 11th, 2021

DOI: https://doi.org/10.21203/rs.3.rs-192946/v1

License: (9) This work is licensed under a Creative Commons Attribution 4.0 International License. Read Full License 
1 The difference of acetabular cup orientation between two surgical sides after

2 primary total hip arthroplasty by right-handed surgeons

3 Ao Xiong ${ }^{1,2,{ }^{*}}$ MD, Su Liu ${ }^{1,2,{ }^{*}}$ MD, Guoqing Li ${ }^{1,2}$ MD, Jian Weng ${ }^{1,2}$ MD, Deli Wang ${ }^{1,2, ~ *}$ MD, Hui

$4 \quad$ Zeng ${ }^{1,2, *} \mathrm{MD}$

$5 \quad{ }^{1}$ Department of Bone \& Joint Surgery, Peking University Shenzhen Hospital, Shenzhen, People’s

6 Republic of China, 518036

$7 \quad{ }^{2}$ National \& Local Joint Engineering Research Center of Orthopaedic Biomaterials, Peking University

8 Shenzhen Hospital, Shenzhen, People's Republic of China, 518036

$9 \quad{ }^{*}$ Corresponding authors:

Deli Wang, 1. Department of Bone \& Joint Surgery, Peking University Shenzhen Hospital, Shenzhen,

PR China, 518036. 2. National \& Local Joint Engineering Research Center of Orthopaedic

Biomaterials, Peking University Shenzhen Hospital, Shenzhen, PR China, 518036. E-mail:

wangdelinavy@163.com.

Hui Zeng, 1. Department of Bone \& Joint Surgery, Peking University Shenzhen Hospital, Shenzhen,

PR China, 518036. 2. National \& Local Joint Engineering Research Center of Orthopaedic

Biomaterials, Peking University Shenzhen Hospital, Shenzhen, PR China, 518036. E-mail:

zenghui_36@163.com.

\section{Abstract}

Background: We performed the retrospective cohort study to compare the acetabular cup surgeons. 
Methods: Between January 2018 and December 2018, 290 patients who aged below 60 years and underwent primary THA were retrospective screened. Patients who had hemiarthroplasty, previous hip surgery, ankylosing spondylitis, developmental dysplasia of hip (DDH, Crowe type-III and typeIV), severe comorbidity, missing information, inferior quality radiographs were excluded. According to the surgery side, all patients were divided into left group and right group. Postoperative plain radiographs were analyzed to compare the AA and IA between left and right side. Univariate and stepwise multivariable linear regression to control included confounding factors. Stratified analysis was performed to identify whether the operation approach can affect the result, including anterolateral (ALA) and posterolateral approach (PLA).

Results: The mean AA was $17.7^{\circ}$ (range $6.0^{\circ}$ to $30.0^{\circ}$ ) and $21.0^{\circ}$ (range $9.5^{\circ}$ to $35.0^{\circ}$ ) for the left and right side respectively. The mean difference was $3.28^{\circ}$ (95\% CI: $\left.1.92-4.64 ; \mathrm{P}<0.001\right)$. The mean IA was $41.1^{\circ}$ (range $24.0^{\circ}$ to $59.0^{\circ}$ ) and $40.1^{\circ}$ (range $20.5^{\circ}$ to $56.0^{\circ}$ ) for the left and right side respectively ( $\mathrm{P}=0.314) .113$ patients' AA within the "safe zone" in the left $(93.4 \%)$, while the right was 93 patients $(82.3 \%)(\mathrm{P}=0.009) .95$ patients' IA within the "safe zone" in the left $(78.5 \%)$, while the right was 97 patients $(85.8 \%)(\mathrm{P}=0.144)$. The IA of ALA group was smaller than PLA group in both sides. The mean difference was $3.98^{\circ}(95 \%$ CI: 1.22 - 6.74; $\mathrm{P}=0.005)$.

Conclusions: We concluded that AA in left side may be more accurate than right side after primary THA by right-handed surgeons. The IA was no difference between the two sides, while it was smaller in ALA than in PLA. The results are still needed to be verified in future.

Keywords: Total hip arthroplasty; Handedness; Surgery side; Anteversion angle; Inclination angle;

Safe zone

\section{Background}


Modern total hip arthroplasty (THA) is the most effective method to relieve pain and disability due to a series of end-stage hip disease [1]. The principle causal indications for THA are osteoarthritis (OA, 90\%), femoral neck fracture (5\%), avascular necrosis (AVN, $2 \%)$, developmental dysplasia of hip (DDH, 2\%) and inflammatory arthritis (1\%) [2]. Accurate acetabular cup position, including anteversion angle (AA) and inclination angle (IA), is critical in THA, as misalignment leads to a higher incidence of dislocation, polyethylene wear, osteolysis, or irritation of the iliopsoas tendon [3-6].

Handedness is defined as the more skillful and flexible of using one hand than the other [7]. The influence of surgeon handedness on surgical procedure and clinical outcomes has been reported previously, especially in general surgery [8], dentistry [9] and urology [10]. Bones are symmetrically distributed in humans, so the surgeons' handedness may have a greater impact on orthopedic surgery than on non-orthopedic surgery [11]. Standing on the right side of the patients during right THA will allow the right-handed surgeon to ream and implant acetabular component comfortably and conveniently. However, it becomes inconvenient when performing the left THA. Up to now, there are extremely limited articles reported the surgeon handedness in orthopedic surgery, especially in primary THA. So, the influence of surgeon handedness on acetabular cup orientation remains unclear.

Therefore, we performed this retrospective cohort study to compare the difference of left and right side primary THA by right-handed surgeon from two aspects: (1) is there any difference between the two sides? (2) which is more accurate?

\section{Methods}

\section{Patients}



who aged below 60 years and underwent primary THA were retrospectively screened. Patients who had hemiarthroplasty $(7,2.4 \%)$, previous hip surgery $(13,4.5 \%)$, ankylosing spondylitis $(5,1.7 \%)$, included (Fig. 1).

290 primary THA patients were consecutively included from January 2018 to December 2018

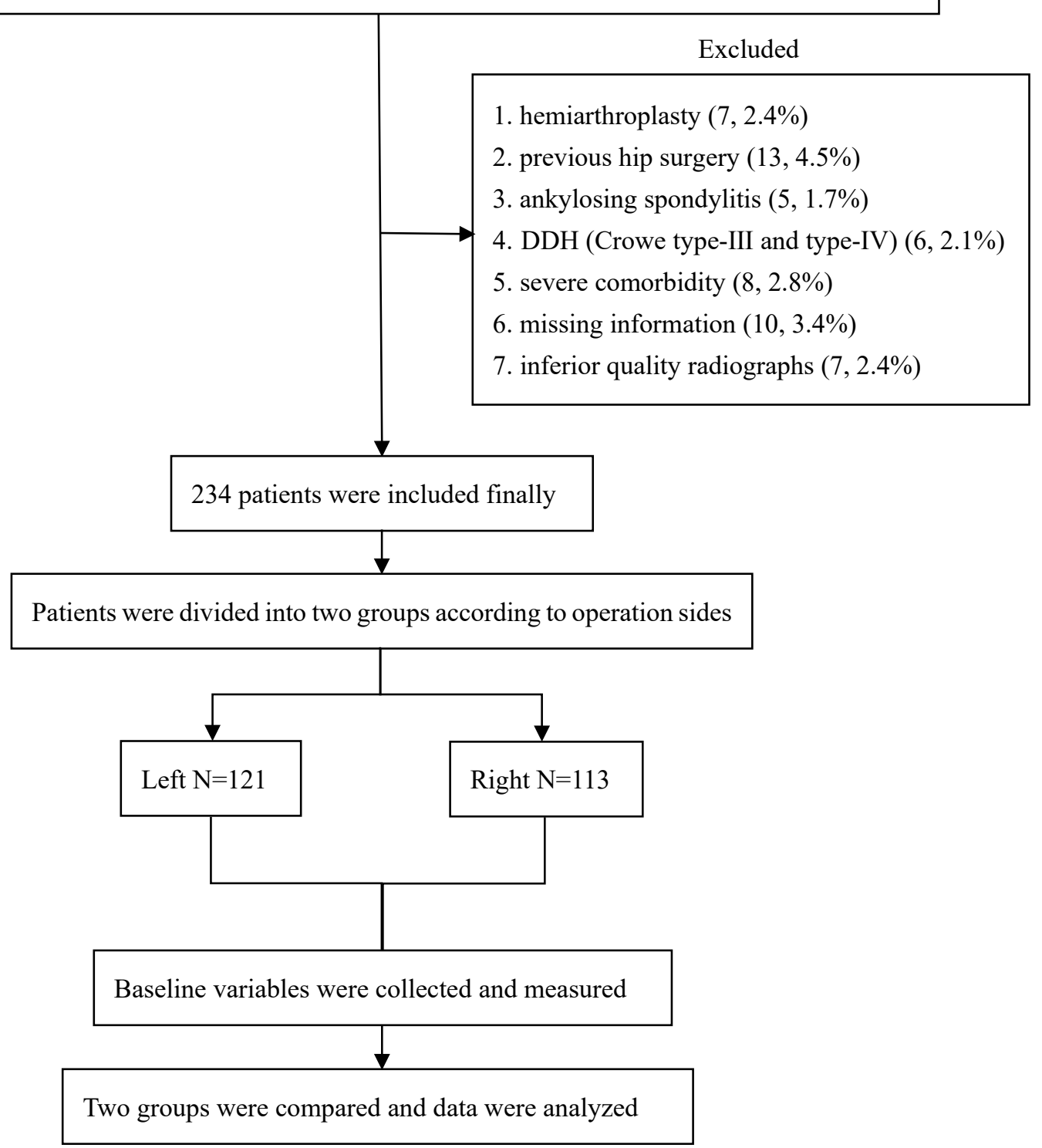

Fig. 1. Flowchart that illustrates patient inclusion and exclusion. THA, total hip arthroplasty; DDH, developmental dysplasia of hip; $\mathrm{N}$, number. 
All surgeries were performed by orthopedic surgeons with more than 20 years of experience, which made the results reliable. The study was approved by the institutional ethics committee at our institution.

\section{Variables}

We conducted the retrospective analysis of all patients' medical records. The data were extracted independently by two researchers. Any difference would be negotiated by a third party. We identified outcomes reported in the previous studies. Radiographic outcomes including AA, IA. Basic demographic information including gender, age, height, weight, body mass index (BMI), diagnosis, operation approach and American Society of Anesthesiologists (ASA).

Postoperative plain radiographs were conducted in anterior-posterior position (AP) of the operation side routinely, which were recorded and evaluated in Picture Archiving and Communication System (PACS). The measurements were made by two researchers independently using a standardized protocol. Only bilateral obturator foramina equally sized would be accepted. The intraclass correlation coefficient (ICC) was calculated to measure the inter-observer reliability for AA and IA. IA is defined as the angle between the long acetabular axis and the horizontal plane and can be directly measured from plain radiographs [12] (Fig. 2). AA is defined as the angle formed by the bottom of the radiographic plate showing the posterior plane of the condyles and the cup opening [12]. The measurement of AA in the AP position of plain radiographs was described in the literature [13] and was shown in the Fig. 2. The values from $30^{\circ}$ to $50^{\circ}$ of IA and $5^{\circ}$ to $25^{\circ}$ of AA were considered as the "safe zone", according to Lewinnek's definition [5].

\section{Statistical analysis}

All statistical analysis was performed by SPSS (IBM version 25.0, Chicago, USA). 


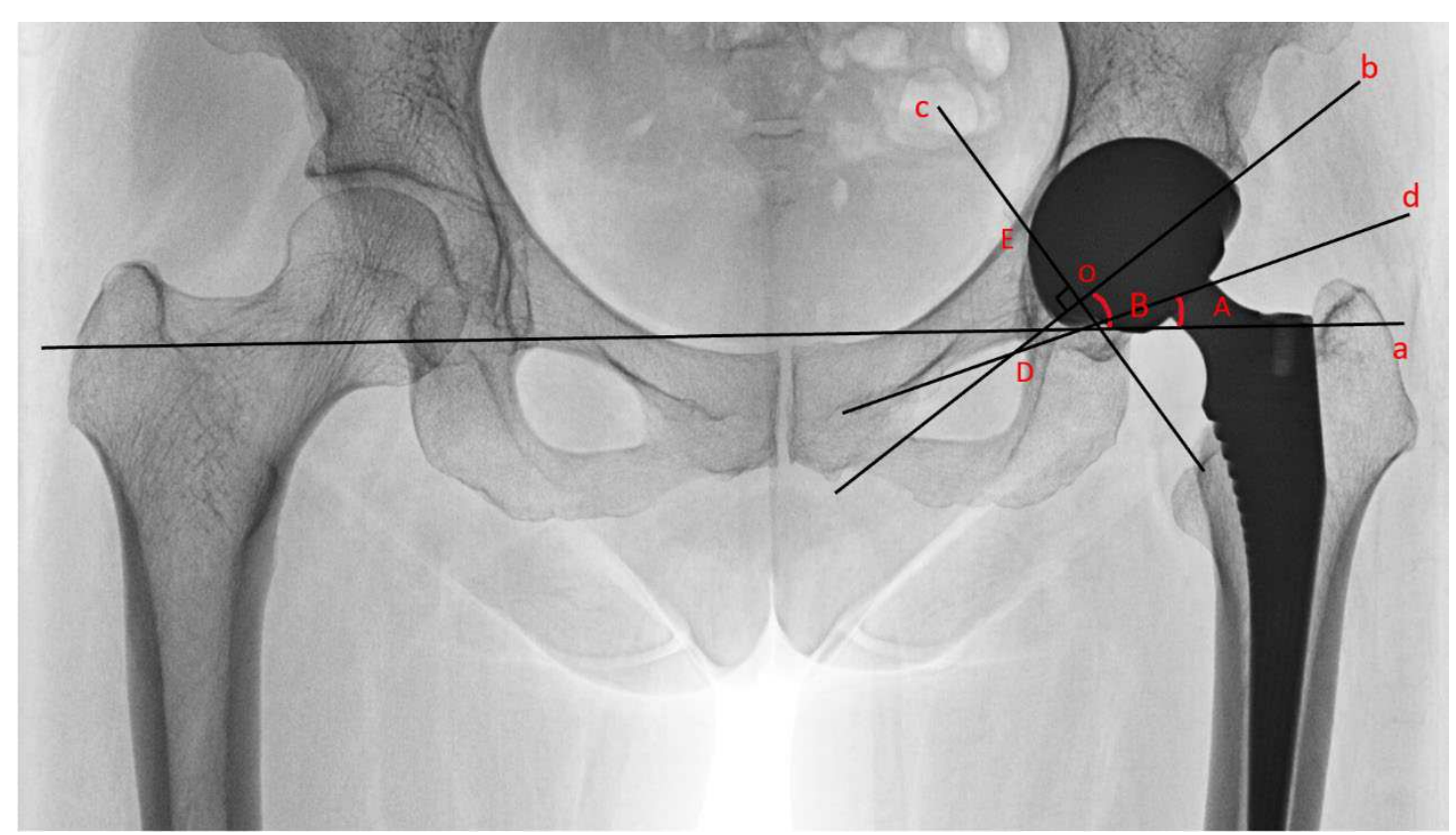

Fig.2 The plain radiograph in anterior-posterior position (AP) of hip after operation. a, the trans-teardrop line; $b$, the line of acetabular cup opening; $c$, the vertical of $b$ from the visible part of the femoral head; $\mathrm{O}$, the intersection of $\mathrm{b}$ and $\mathrm{c}$; $\mathrm{E}$, the intersection of $\mathrm{c}$ and acetabular cup in the plain radiograph; $\mathrm{D}$, $\mathrm{OE}=\mathrm{OD} ; \mathrm{d}$, the line between $\mathrm{D}$ and the intersection of femoral and cup in the plain radiograph; $\mathrm{A}$, the anteversion angle; $\mathrm{B}$, the inclination angle.

Continuous variables were described by mean \pm standard deviation (SD), and categorical variables were described by number and percentage. For continuous variables, KolmogorovSmirnov test was applied for normal distribution while Mann-Whitney U test for non-normal distribution. Chi-square test and Fisher's exact test were applied to test categorical variables. Baseline variables considered clinically relevant or univariate in relation to outcomes were included in the multiple linear regression model. Considering the number of events available, the included variables were carefully selected to ensure parsimony of the final model. All statistics were 2-tailed, $\mathrm{p}<0.05$ were considered statistical significance, $\mathrm{p}<0.001$ were considered dramatically statistical significance [14]. Scatter plots of the variables were graphically presented. Stratified analysis was performed according to different operation approach, including anterolateral (ALA) and posterolateral approach (PLA). ICC was measured and estimated using the grouping recommended by Landis and Koch [15]. A score between 0.61 and 0.8 indicated substantial content, while a score 
higher than 0.81 indicated near-perfect agreements content.

\section{Results}

There were 234 patients (109 female and 125male) fulfilled the inclusion criteria and were recruited for the final analysis. According to the operation side, they were grouped into the left $(\mathrm{N}=121)$ and the right $(\mathrm{N}=113)$. Among all of the enrolled participations, the mean age was $44.35 \pm 11.32$ (22-60) years, the mean BMI was $22.77 \pm 3.36(14.5-35.2) \mathrm{kg} / \mathrm{m}^{2}$.

Pre-operative baseline characteristics were collected and analyzed. Reasons for THA were: degeneration $(\mathrm{N}=34)$, rheumatoid arthritis $(\mathrm{RA}, \mathrm{N}=13)$, fracture $(\mathrm{N}=26), \mathrm{AVN}(\mathrm{N}=107)$ and $\mathrm{DDH}$ $(\mathrm{N}=54)$. There was no statistical significance among all of the baseline variables: gender, age, BMI, diagnosis, ASA and operation approach (Table 1). The mean AA was $17.7^{\circ}$ (range $6.0^{\circ}$ to $30.0^{\circ}$ ) and $21.0^{\circ}$ (range $9.5^{\circ}$ to $35.0^{\circ}$ ) for the left and right side respectively. The mean difference was $3.28^{\circ}$ (95\% CI: $1.92-4.64 ; \mathrm{t}=-4.741, \mathrm{P}<0.001)$ (Table 2$)$. The mean IA was $41.1^{\circ}\left(\right.$ range $24.0^{\circ}$ to $\left.59.0^{\circ}\right)$ and $40.1^{\circ}$ (range $20.5^{\circ}$ to $56.0^{\circ}$ ) for the left and right side respectively. There was no statistical significance in AA between the two sides $(\mathrm{P}=0.314)$. There were two outliers in the right side (137,138; Fig.3A) After removing the two outliers, there were still no statistical significance in AA between the two sides $(\mathrm{P}=0.502)$ (Fig.3B). The IA of ALA group was smaller than PLA group in both sides $(\mathrm{P}=0.005)$. The mean difference was $3.98^{\circ}(95 \% \mathrm{CI}: 1.22-6.74 ; \mathrm{t}=-2.840, \mathrm{P}=0.005)$ (Table 3). Scatter plots of AA and IA between the two sides were graphically presented in Fig. 4.

There were 113 patients' AA within the "safe zone" in the left group (93.4\%), while the right was 93 patients ( $82.3 \%)$. It was statistical significance $(\mathrm{P}=0.009)$. There were 95 patients' IA within the "safe zone" in the left group (78.5\%), while the right was 97 patients (85.8 \%). It was no statistical significance ( $\mathrm{P}=0.144)$ (Table 4). There was no difference in AA $(\mathrm{P}=0.165)$ and IA $(\mathrm{P}=0.342)$ 
between the two sides after primary THA by ALA (Table 5). The AA was smaller in the left side than in the right side after primary THA by PLA (mean difference $=3.25^{\circ}, 95 \%$ CI: $1.85-4.65$; $\mathrm{t}=-$ 4.572, $\mathrm{P}<0.001$ ), while the IA was no difference $(\mathrm{P}=0.393)$ (Table 6). Analysis of inter-observer correlation coefficients for AA (ICC 0.814, $\mathrm{P}<0.001$ ), and IA (ICC 0.906, $\mathrm{P}<0.001$ ) were excellent.

\section{Table 5}

153 AA and IA after primary THA by ALA between left and right side $(\mathrm{N}=33)$

\begin{tabular}{ccccccc}
\hline \multirow{2}{*}{ Variables } & \multirow{2}{*}{ Categories } & \multicolumn{2}{c}{ Left $(\mathrm{N}=18)$} & \multicolumn{2}{c}{ Right $(\mathrm{N}=15)$} & \multirow{2}{*}{$p$ Value $^{\#}$} \\
\cline { 3 - 6 } & & Count & Description & Count & Description & \\
\hline $\mathrm{AA}\left(^{\circ}\right)$ & Mean $\pm \mathrm{SD}$ & 18 & $16.75 \pm 6.69$ & 15 & $20.10 \pm 6.80$ & 0.165 \\
$\mathrm{IA}\left(^{\circ}\right)$ & Mean $\pm \mathrm{SD}$ & 18 & $38.00 \pm 6.11$ & 15 & $36.13 \pm 4.73$ & 0.342 \\
\hline
\end{tabular}

Abbreviations: AA, anteversion angle; IA, inclination angle; THA, total hip arthroplasty; ALA, anterolateral approach; N, number; SD, standard deviation.

$\#, \mathrm{p}<0.05$, statistical significance.

\section{Table 6}

AA and IA after primary THA by PLA between left and right side $(\mathrm{N}=201)$

\begin{tabular}{ccccccc}
\hline \multirow{2}{*}{ Variables } & \multirow{2}{*}{ Categories } & \multicolumn{2}{c}{ Left $(\mathrm{N}=103)$} & \multicolumn{2}{c}{ Right $(\mathrm{N}=98)$} & \multirow{2}{*}{$p$ Value } \\
\cline { 3 - 6 } & & Count & Description & Count & Description & \\
\hline AA $\left(^{\circ}\right)$ & Mean \pm SD & 103 & $17.87 \pm 5.17$ & 98 & $21.12 \pm 4.89$ & $<0.001^{\#}$ \\
IA $\left(^{\circ}\right)$ & Mean \pm SD & 103 & $41.59 \pm 8.10$ & 98 & $40.65 \pm 7.33$ & 0.393 \\
\hline
\end{tabular}

Abbreviations: AA, anteversion angle; IA, inclination angle; THA, total hip arthroplasty; PLA, posterolateral approach; N, number; SD, standard deviation.

\#, $\mathrm{p}<0.001$, dramatically statistical significance.

\section{Discussion}

We performed the current study to compare the difference of AA and IA in left and right side primary THA by right-handed orthopedic surgeons. Our results were different with Song's [16].

Song et al. conducted a study to investigate the difference of AA and IA in bilateral THA by righthanded surgeons using PLA. They found that the mean AA was $25.28^{\circ}$ in left side and $22.01^{\circ}$ in right side, which were larger than us (left $17.87^{\circ}$, right $21.12^{\circ}$ ) (Table 6). However, the mean IA was smaller than us (left $37.50^{\circ}$ vs $41.59^{\circ}$; right $38.59^{\circ}$ vs $40.65^{\circ}$ ) (Table 6). Take Lewinnek 's opinion [5] as standard, $52 \%$ of AA and $87 \%$ of IA of left side was within the "safe zone", while 
$71 \%$ of AA and $88 \%$ of IA of right side was within the "safe zone". Both of the percentage of AA and IA within "safe zone" were smaller than us. They thought that the placement of cup in dominant hand side was more accurate than in the non-dominant hand side, which was contrary to us. In Kong's study [17], the AA in left side was $22.44^{\circ}$, which was smaller than right side $24.77^{\circ}$. In Pennington et al. 's study [18], they found that the difference of AA was $3^{\circ}$ between the dominant and non-dominant side of surgeons, which was a little smaller than our study.

Combined with previous studies, we could recognize that surgeon handedness may be have an effect on AA. And we could assume that the AA in non-dominant hand side may be smaller than dominant hand side, but it remains unclear which is much better. Several studies [19-21] had reported that AA in THA was a key factor which was related to hip component dislocation. The reason why handedness has an effect on orthopedic surgery was not unclear. We assumed that the standing position may directly affects the accuracy of spatial positioning, and the unaccustomed perspective would further lead to visual errors. In addition, the left and right hand performs completely different tasks during the whole surgery. Therefore, when dominant hand or nondominant hand dominates a surgical procedure, there are difference in AA.

Operation approach has been discussed affecting the cup orientation [22], so we performed a stratified analysis. After stratified analysis, the AA in the left side was smaller than right side by PLA (mean difference $=3.25^{\circ}, 95 \%$ CI: $1.85-4.65 ; \mathrm{t}=-4.572, \mathrm{P}<0.001$ ), while was no difference by ALA ( $\mathrm{P}=0.165)$. According to the mean difference $\left(3.35^{\circ}\right)$, we suspected that it may be due to the small sample size in ALA group. Whether in left side or right side, the IA was no statistical difference both in ALA group ( $\mathrm{P}=0.342)$ and PLA group $(\mathrm{P}=0.393)$. Combined with the results discussed above, we can find that the AA was affected by handedness of orthopedic surgeon and left 
side was smaller than right side by right-handed surgeon. The results were unrelated to operation approach. However, the question "which is more accurate?" is still under debating.

The concept of "safe zone" has to be a matter of recent controversy [20, 23]. Some researchers $[19,24-26]$ have questioned whether the historical concept of "safe zone" has clinical significance. Historical "safe zone" did not take into account individual patients' morphology that might alter component positions, such as changes in pelvic tilt, which has been proved to alter the position of acetabular cup. Danoff et al. [26] suggested that AA should be adjusted to start from $10^{\circ}$ to reduce the risk of dislocation. Widmer et al. [27] thought that AA was set at $10-30^{\circ}$ can effectively prevent femoral neck impingement. Callanan et al. [28] renewed the "safe zone" and found that it can 't reduce the rate of dislocation. Although the component position has been identified to play a role in hip stability and risk of postoperative dislocation, the evidence for "safe zone" of component position is limited. This may be due to the difference between the surgical approach, methods of measuring and limitation in statistical power [29, 30].

There are several limitations in the study. (1) The study only included right-handed surgeons, and the results in this study may be biased by individual surgeons rather than the general phenomenon. To reduce the inherent bias, the left-handed surgeons should be included in the future. (2) As a retrospective study, the effects of confounders cannot be completely excluded. However, the current study compared the basic characteristics of the two groups, which were likely affect the results, and all of the included variables were consistent. (3) The surgeries were conducted by two orthopedic surgeons. However, both the two surgeons had more than 20-year operating experience and can perform at least 250 surgeries per year, so it can be considered that the two surgeons were consistent in terms of surgical ability. (4) The study used the 2-D radiographic imaging, and the measurements 
may be affected by pelvic tilt and rotation. But only bilateral obturator foramina equally sized accepted, which can be considered to be controlled [31]. Although computerized tomography (CT) is more accurate than plain radiograph, Lu et al. [32] and Nho et al. [33] reported that the results measured by plain radiograph were basically consistent with those measured by CT. (5) Although the study concluded that AA was smaller in left side than right side, the postoperative complications, quality of life, and the rate of revision were still unknown.

In a word, surgeon handedness affecting AA after primary THA was proved. However, which is more accurate in placing cup orientation, dominant hand side or non-dominant hand side, remains uncertain. This problem is closely related to the surgeon 's procedure during primary THA. It is still need large sample studies, including left and right-handed surgeons, to solve this problem in the future.

\section{Conclusion}

From the study, we concluded that AA in left side may be more accurate than right side after primary THA by right-handed surgeons. The IA was no difference between the two sides, while it was smaller in ALA than in PLA. The results are still needed to be verified in future.

\section{Abbreviations} coefficient; SD: standard deviation; RA: rheumatoid arthritis; N: number; $\mathrm{CT}$ : computerized tomography. 
We have obtained oral consent from the participants and ethical approval from the ethics committee. The ethical review was approved by the Human Subjects Committee of the Ethics Committee of Peking University Shenzhen Hospital (2019).

\section{Consent for publication}

We have got an agreement on publication.

\section{Availability of data and materials}

All data collected or analyzed in the study were included in this published article.

\section{Competing interests}

There were no competing interests.

\section{Funding}

This study was supported by grants from Shenzhen Key Medical Subject (No. SZXK023), Shenzhen "San-Ming” Project of Medicine (No. SZSM201612092), Guangdong Basic and Applied

Basic Research Foundation (No. 2019A1515011290), Shenzhen Research and Development

Projects (No. JCYJ20170307111755218), Shenzhen Research and Development Projects (No. JCYJ20190809110807421), Scientific research project of health and family planning system in Shenzhen (No. SZXJ2018077), The basic research project of Peking University Shenzhen Hospital (No. JCYJ2018004).

\section{Author's contribution}

Ao Xiong and Su Liu participated in the design and manuscript writing; Su Liu and Guoqing Li participated in the data collection and imaging measurement; Jian Weng participated in the data review and statistical analysis; Deli Wang and Hui Zeng participated in the design of the study, and 
reviewed the final manuscript.

\section{Acknowledgements}

Not applicable.

\section{References}

1. Shan L, Shan B, Graham D, et al. Total hip replacement: a systematic review and metaanalysis on mid-term quality of life. Osteoarthritis Cartilage. 2014; 22. p. 389-406.

2. Rory J Ferguson, Antony JR Palmeret, Adrian Taylor, et al. Hip replacement. The Lancet. 2018; 392. p. 1662-1671.

3. Dora C, Houweling M, Koch $\mathrm{P}$, et al. Iliopsoas impingement after total hip replacement: the results of non-operative management, tenotomy or acetabular revision. J Bone Joint Surg Br. 2007;89:1031-5.

4. Kennedy JG, Rogers WB, Soffe KE, et al. Effect of acetabular component orientation on recurrent dislocation, pelvic osteolysis, polyethylene wear, and component migration. J Arthroplasty. 1998;13:530-4.

5. Lewinnek GE, Lewis JL, Tarr R, et al. Dislocations after total hip-replacement arthroplasties. J Bone Joint Surg Am. 1978;60:217-20.

6. Peng HM, Feng B, Chen X, et al. Usefulness of a Simple Preoperative Planning Technique using Plain X-rays for Direct Anterior Approach for Total Hip Arthroplasty. Orthop Surg. 2020; doi:10.1111/os.

7. Badalato GM, Shapiro E, Rothberg MB, et al. The da vinci robot system eliminates multispecialty surgical trainees' hand dominance in open and robotic surgical settings. JSLS. $2014 ; 18$. 
281 8. Grantcharov TP, Bardram L, Funch-Jensen P, et al. Impact of hand dominance, gender, and experience with computer games on performance in virtual reality laparoscopy. Surg Endosc. $2003 ; 17$. p. 1082-5.

9. Canakci Varol, Tan Uner, Orbak Recep, et al. Right- and left-handed dentists in periodontal therapy. Int. J. Neurosci. 2002;112:1-14.

10. Lipsky MJ, Motamedinia P, Ko WJ, et al. Is there a difference in laterality during robot-

11. Moloney D, Bishay M, Ivory J, et al. Failure of the sliding hip screw in the treatment of femoral neck fractures: 'left-handed surgeons for left-sided hips'. Injury. 1994; null: B9-13.

12. BM Jolles, P Zangger, and PF Leyvraz. Factors predisposing to dislocation after primary

13. Bachhal V, Jindal N, Saini G, et al. A new method of measuring acetabular cup anteversion

14. SJ Pocock, and GW Stone. The Primary Outcome Is Positive - Is That Good Enough? N

16. Song X, Ni M, Li H, et al. Is the cup orientation different in bilateral total hip arthroplasty and Research. 2018; 13.

17. Kong X, Yang M, Li X, et al. Impact of surgeon handedness in manual and robot-assisted 
total hip arthroplasty. J Orthop Surg Res. 2020;15. p. 159.

18. Pennington N, Redmond A, Stewart T, et al. The impact of surgeon handedness in total hip replacement. Ann R Coll Surg Engl. 2014;96. p. 437-41.

19. Elkins JM, JJ Callaghan, and TD Brown. The 2014 Frank Stinchfield Award: The 'landing zone' for wear and stability in total hip arthroplasty is smaller than we thought: a computational analysis. Clin Orthop Relat Res. 2015;473. p. 441-52.

20. Abdel MP, Roth P, Jennings MT, et al. What Safe Zone? The Vast Majority of Dislocated THAs Are Within the Lewinnek Safe Zone for Acetabular Component Position. Clin Orthop Relat Res. 2016;474. p. 386-91.

21. Fujishiro T, Hiranaka T, Hashimoto S, et al. The effect of acetabular and femoral component version on dislocation in primary total hip arthroplasty. Int Orthop. 2016;40. p. 697-702.

22. Grammatopoulos G, Pandit HG, da Assuncao R, et al. The relationship between operative and radiographic acetabular component orientation: which factors influence resultant cup orientation? Bone Joint J. 2014;96- B(10):1290-7.

23. Seagrave KG, Troelsen A, Malchau H, et al. Acetabular cup position and risk of dislocation in primary total hip arthroplasty. Acta Orthop. 2017;88. p. 10-17.

24. Yoon YS, Hodgson AJ, Tonetti J, et al. Resolving inconsistencies in defining the target orientation for the acetabular cup angles in total hip arthroplasty. Clin Biomech (Bristol, Avon). 2008;23. p. 253-9.

25. Tiberi JV, Antoci V, Malchau H, et al. What is the Fate of Total Hip Arthroplasty (THA) Acetabular Component Orientation When Evaluated in the Standing Position? J Arthroplasty. 2015;30. p. 1555-60. 
26. Danoff JR, Bobman J, Cunn G, et al. Redefining the Acetabular Component Safe Zone for Posterior Approach Total Hip Arthroplasty. J Arthroplasty. 2016;31. p. 506-11.

27. Widmer, $\mathrm{KH}$ and B Zurfluh. Compliant positioning of total hip components for optimal

28. Callanan MC, Jarrett B, Bragdon CR, et al. The John Charnley Award: risk factors for cup

Table 1

Baseline characteristics of primary THA patients between left and right side $(\mathrm{N}=234)$

\begin{tabular}{|c|c|c|c|c|c|c|}
\hline \multirow{2}{*}{ Variables } & \multirow{2}{*}{ Categories } & \multicolumn{2}{|c|}{ Left $(\mathrm{N}=121)$} & \multicolumn{2}{|c|}{ Right $(\mathrm{N}=113)$} & \multirow{2}{*}{$p$ Value } \\
\hline & & Count & Description & Count & Description & \\
\hline
\end{tabular}




\begin{tabular}{ccccccc}
\hline \multirow{2}{*}{ Gender } & Female & 56 & $46.3 \%$ & 53 & $46.9 \%$ & 0.924 \\
& Male & 65 & $53.7 \%$ & 60 & $53.1 \%$ & \\
Age (years) & Median & 121 & 47.00 & 113 & 46.00 & 0.574 \\
BMI $\left(\mathrm{kg} / \mathrm{m}^{2}\right)$ & Mean \pm SD & 121 & $22.65 \pm 3.55$ & 113 & $22.90 \pm 3.15$ & 0.582 \\
& degeneration & 19 & $15.7 \%$ & 15 & $13.3 \%$ & \\
Diagnosis & RA & 6 & $5.0 \%$ & 7 & $6.2 \%$ & \\
& fracture* & 13 & $10.7 \%$ & 13 & $11.5 \%$ & 0.938 \\
& AVN & 57 & $47.1 \%$ & 50 & $44.2 \%$ & \\
& DDH** & 26 & $21.5 \%$ & 28 & $24.8 \%$ & \\
ASA & 1 & 65 & $53.7 \%$ & 64 & $56.6 \%$ & \\
& 2 & 51 & $42.1 \%$ & 46 & $40.7 \%$ & 0.782 \\
& 3 & 5 & $4.1 \%$ & 3 & $2.7 \%$ & \\
\hline \multirow{2}{*}{ Approach } & ALA & 18 & $14.9 \%$ & 15 & $13.3 \%$ & 0.725 \\
& PLA & 103 & $85.1 \%$ & 98 & $86.7 \%$ & \\
\hline
\end{tabular}

Abbreviations: THA, total hip arthroplasty; N, number; SD, standard deviation; BMI, body mass index;

348 RA, rheumatoid arthritis; AVN, aseptic vascular necrosis; DDH, developmental dysplasia of the hip;

349 ASA, American Society of Anesthesiologists; ALA, anterolateral approach; PLA, posterolateral

350 approach.

$351 \quad \#, \mathrm{p}<0.05$, statistical significance;

$352 *$, Fracture included femoral neck fracture and intertrochanteric fracture, but there was no significant

353 displacement;

$354 * *$, DDH only included Crowe type-I and type-II.

\section{Table 2}

357 Univariate and stepwise multivariable linear regression of AA after THA $(\mathrm{N}=234)$

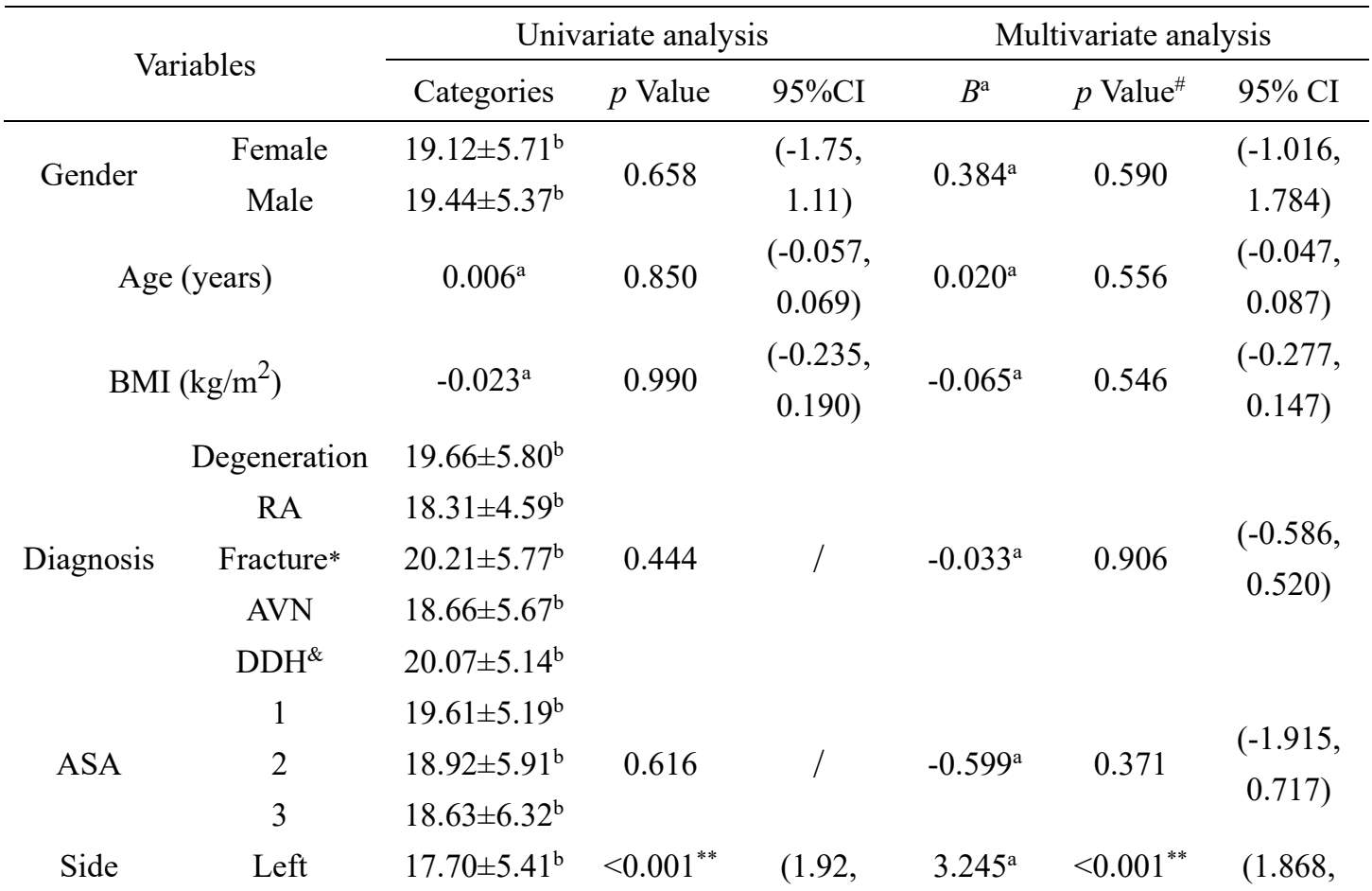


0.195

$(6,35)$

$1.084^{\mathrm{a}}$

0.287

$(-0.918$,

Abbreviations: AA, anteversion angle; THA, total hip arthroplasty; N, number; CI, confidence interval; BMI, body mass index; RA, rheumatoid arthritis; AVN, aseptic vascular necrosis; DDH, developmental dysplasia of the hip; ASA, American Society of Anesthesiologists; ALA, anterolateral approach; PLA, posterolateral approach.

a, Unstandardized Coefficients Beta;

b, mean $\pm \mathrm{SD}$; SD, standard deviation;

c, median;

**, $\mathrm{p}<0.001$, dramatically statistical significance;

$\#, \mathrm{p}<0.05$, statistical significance;

*, Fracture included femoral neck fracture and intertrochanteric fracture, but there was no significant displacement;

\&, DDH only included Crowe type-I and type-II.

\section{Table 3}

Univariate and stepwise multivariable linear regression of IA after THA $(\mathrm{N}=234)$

\begin{tabular}{|c|c|c|c|c|c|c|c|}
\hline \multirow{2}{*}{\multicolumn{2}{|c|}{ Variables }} & \multicolumn{3}{|c|}{ Univariate analysis } & \multicolumn{3}{|c|}{ Multivariate analysis } \\
\hline & & Categories & $p$ Value & $95 \% \mathrm{CI}$ & $B^{\mathrm{a}}$ & $p$ Value & $95 \% \mathrm{CI}$ \\
\hline \multirow{2}{*}{ Gender } & Female & $40.50 \pm 8.57^{b}$ & \multirow{2}{*}{0.896} & $(-2.13$ & \multirow{2}{*}{$0.328^{\mathrm{a}}$} & \multirow{2}{*}{0.744} & $(-1.646$ \\
\hline & Male & $40.63 \pm 6.62^{b}$ & & $1.86)$ & & & $2.302)$ \\
\hline \multicolumn{2}{|c|}{ Age (years) } & $-0.025^{\mathrm{a}}$ & 0.569 & $\begin{array}{c}(-0.112 \\
0.061)\end{array}$ & $0.001^{\mathrm{a}}$ & 0.984 & $\begin{array}{c}(-0.093 \\
0.095)\end{array}$ \\
\hline \multicolumn{2}{|c|}{ BMI $\left(\mathrm{kg} / \mathrm{m}^{2}\right)$} & $-0.002^{a}$ & 0.835 & $\begin{array}{c}(-0.294 \\
0.290)\end{array}$ & $-0.060^{\mathrm{a}}$ & 0.692 & $\begin{array}{c}(-0.359 \\
0.239)\end{array}$ \\
\hline \multirow{5}{*}{ Diagnosis } & Degeneration & $40.78 \pm 7.96^{b}$ & \multirow{5}{*}{0.467} & \multirow{5}{*}{ / } & \multirow{5}{*}{$0.265^{\mathrm{a}}$} & \multirow{5}{*}{0.504} & \multirow{5}{*}{$\begin{array}{c}(-0.515 \\
1.045)\end{array}$} \\
\hline & RA & $38.54 \pm 10.18^{b}$ & & & & & \\
\hline & Fracture* & $40.46 \pm 7.69^{b}$ & & & & & \\
\hline & AVN & $40.03 \pm 6.47^{b}$ & & & & & \\
\hline & $\mathrm{DDH}^{\&}$ & $42.01 \pm 8.60^{b}$ & & & & & \\
\hline \multirow{3}{*}{ ASA } & 1 & $41.23 \pm 7.22^{\mathrm{b}}$ & \multirow{3}{*}{0.333} & \multirow{3}{*}{ / } & \multirow{3}{*}{$-0.891^{\mathrm{a}}$} & \multirow{3}{*}{0.345} & \multirow{3}{*}{$\begin{array}{c}(-2.747 \\
0.965)\end{array}$} \\
\hline & 2 & $39.72 \pm 7.96^{b}$ & & & & & \\
\hline & 3 & $40.25 \pm 8.39^{b}$ & & & & & \\
\hline \multirow{2}{*}{ Side } & Left & $41.05 \pm 7.92^{b}$ & \multirow{2}{*}{0.314} & $(-0.95$ & \multirow{2}{*}{$-1.105^{\mathrm{a}}$} & \multirow{2}{*}{0.263} & $(-3.046$ \\
\hline & Right & $40.05 \pm 7.19^{b}$ & & 2.95) & & & $0.836)$ \\
\hline \multirow{2}{*}{ Approach } & ALA & $37.15 \pm 5.52^{b}$ & \multirow{2}{*}{$0.005^{* *}$} & $(1.22$ & \multirow{2}{*}{$3.846^{\mathrm{a}}$} & \multirow{2}{*}{$0.008^{* *}$} & $(1.022$ \\
\hline & PLA & $41.13 \pm 7.73^{b}$ & & $6.74)$ & & & $6.670)$ \\
\hline
\end{tabular}
BMI, body mass index; RA, rheumatoid arthritis; AVN, aseptic vascular necrosis; DDH, developmental dysplasia of the hip; ASA, American Society of Anesthesiologists; ALA, anterolateral approach; PLA, posterolateral approach. 
b, mean $\pm \mathrm{SD}$; SD, standard deviation;

*, Fracture included femoral neck fracture and intertrochanteric fracture, but there was no significant displacement;

$* *, \mathrm{p}<0.05$, statistical significance;
$\&$, DDH only included Crowe type-I and type-II.

Table 4

Analysis the proportion of AA and IA in the "safe zone" between left and right side ( $\mathrm{N}=234)$

\begin{tabular}{|c|c|c|c|c|c|c|}
\hline \multirow{2}{*}{ Variables } & \multirow{2}{*}{ Categories } & \multicolumn{2}{|c|}{ left $(\mathrm{N}=121)$} & \multicolumn{2}{|c|}{ right $(\mathrm{N}=113)$} & \multirow{2}{*}{$p$ Value } \\
\hline & & Count & Description & Count & Description & \\
\hline \multirow{2}{*}{$\mathrm{AA}\left({ }^{\circ}\right)$} & Safe & 113 & $93.4 \%$ & 93 & $82.3 \%$ & \multirow{2}{*}{0.009} \\
\hline & Non-safe & 8 & $6.6 \%$ & 20 & $17.7 \%$ & \\
\hline \multirow{2}{*}{$\mathrm{IA}\left({ }^{\circ}\right)$} & Safe & 95 & $78.5 \%$ & 97 & $85.8 \%$ & \multirow{2}{*}{0.144} \\
\hline & Non-safe & 26 & $21.5 \%$ & 16 & $14.2 \%$ & \\
\hline
\end{tabular}

Abbreviations: AA, anteversion angle; IA, inclination angle; $\mathrm{N}$, number.

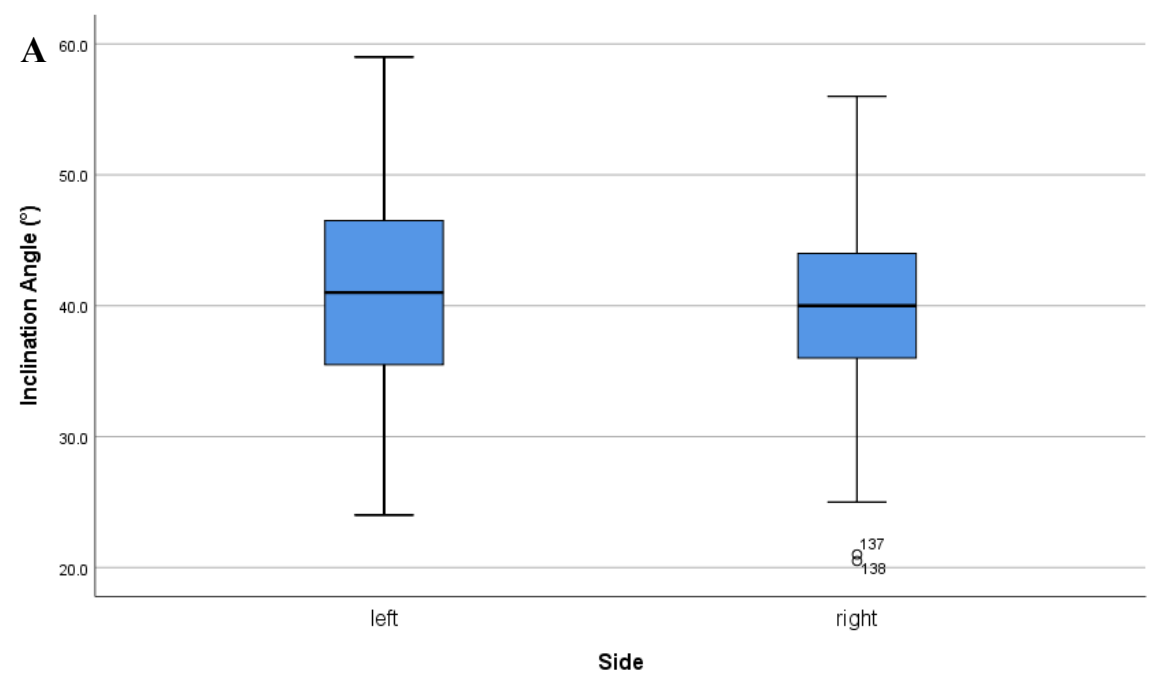




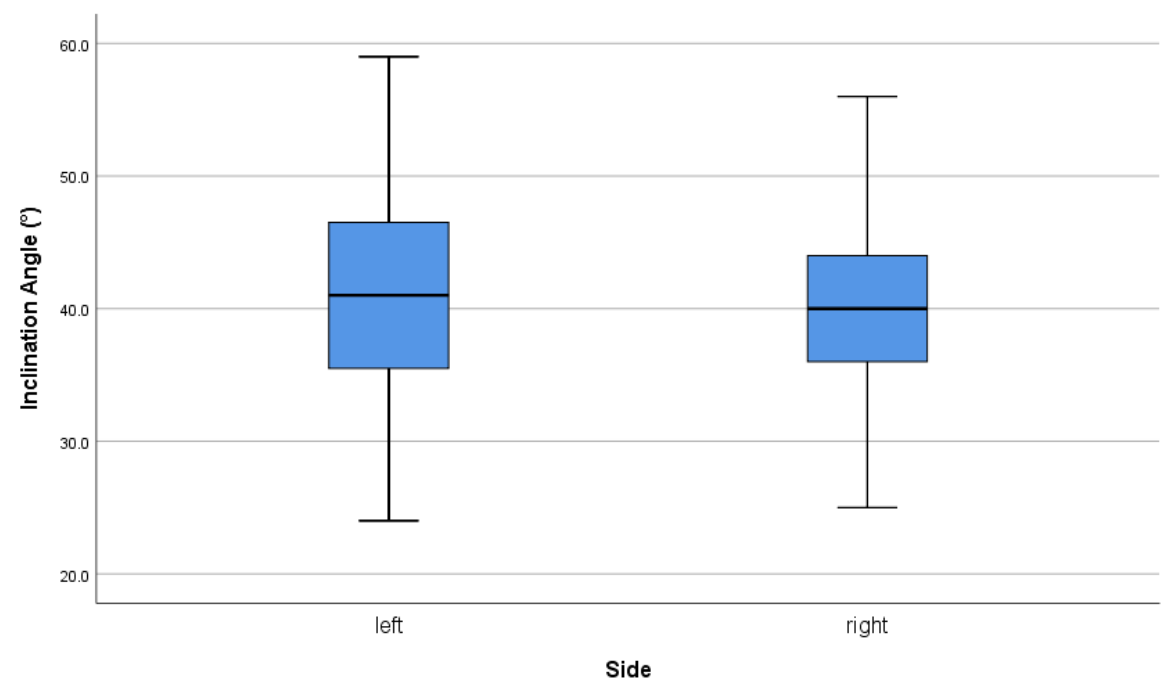

403

404

405

406

Fig. 3. Box plot of inclination angle in both sides. (A) There are two outliers in the right side. (B) Remove the two outliers in the right side. No significant difference between A and B.

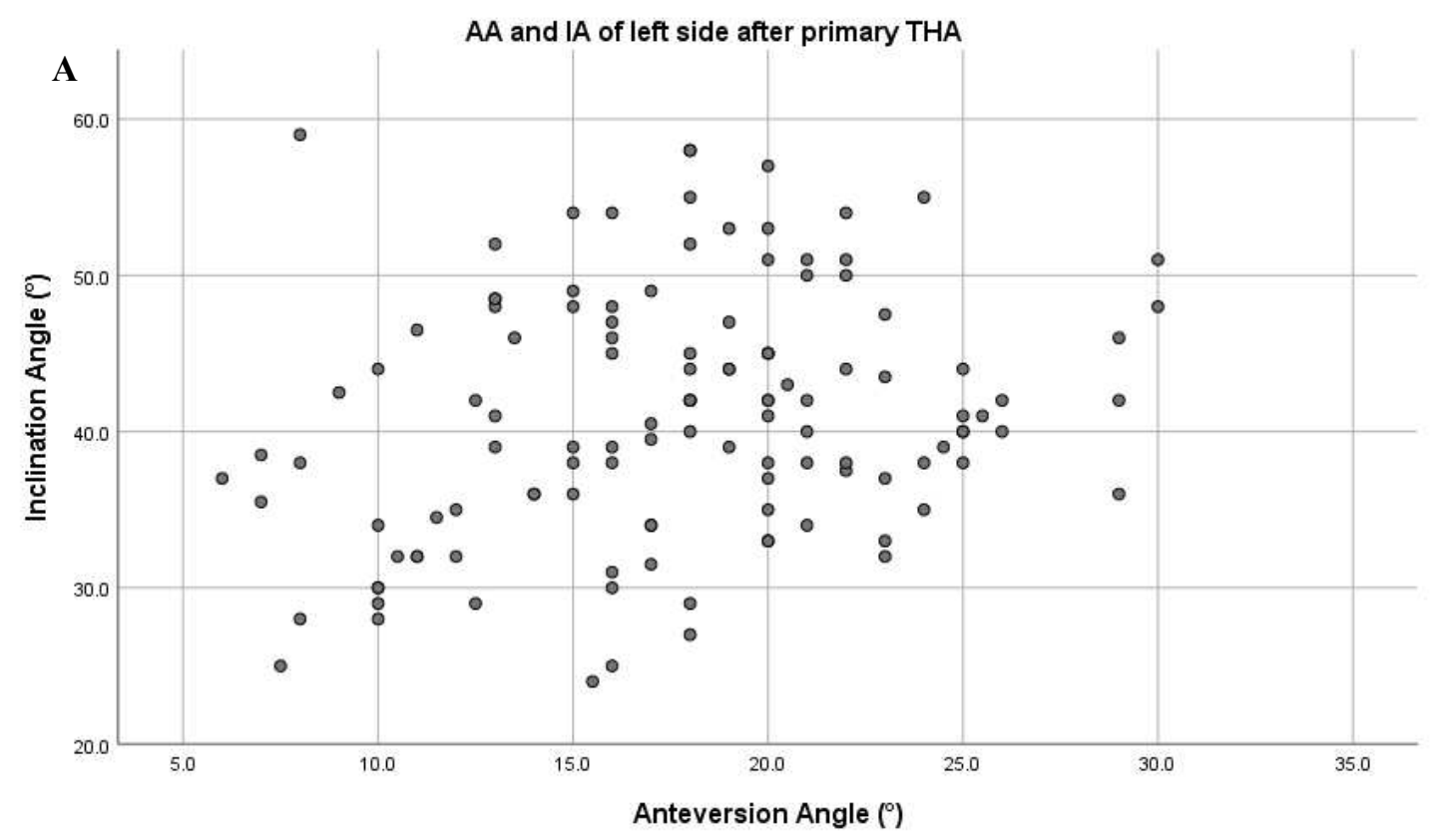




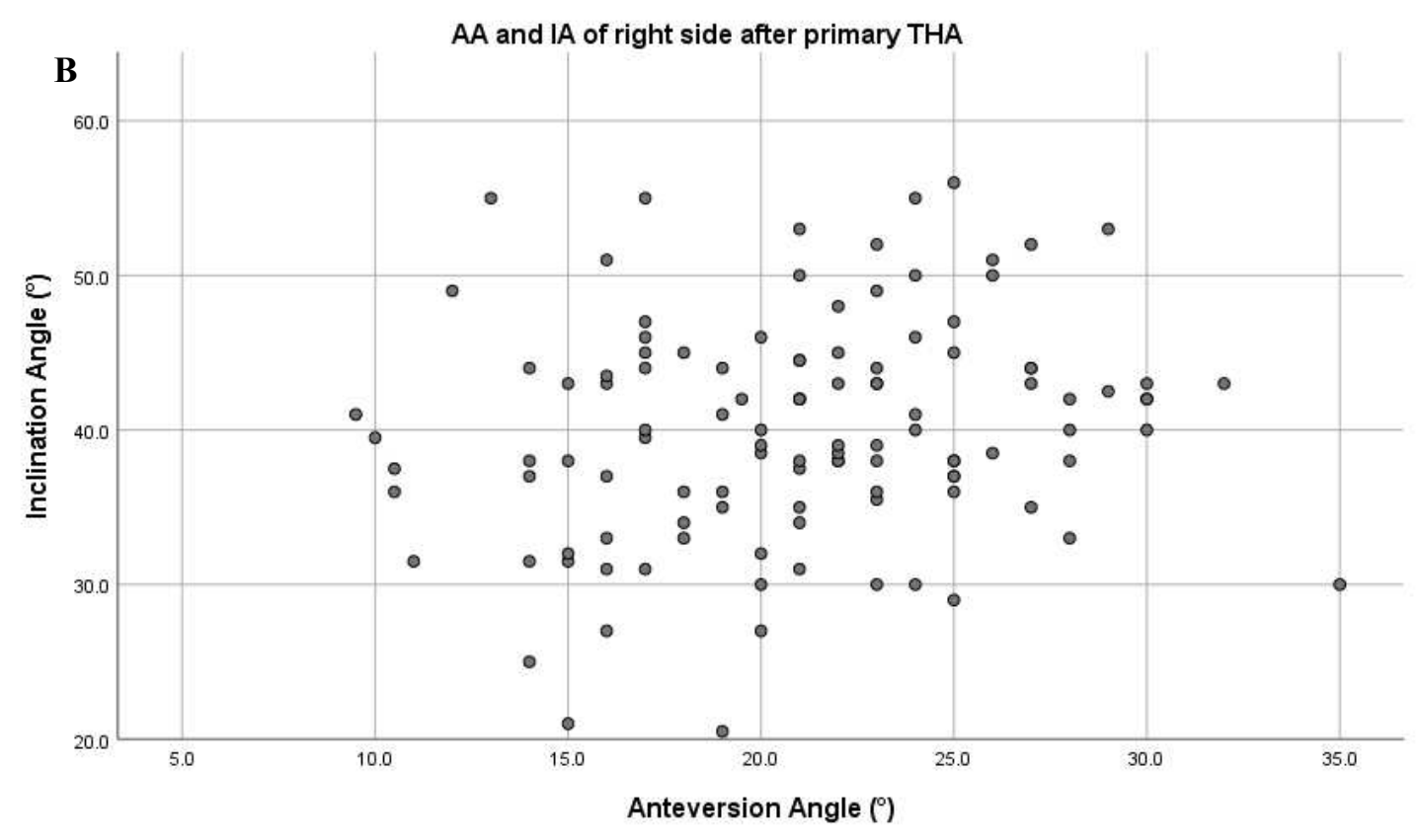

408

409

410

411

412

413

414

415

416

Fig. 4. (A) Scatterplot of AA and IA of left side after primary THA. (B) Scatterplot of AA and IA of right side after primary THA. THA, total hip arthroplasty. 


\section{Figures}

290 primary THA patients were consecutively included from January 2018 to December 2018

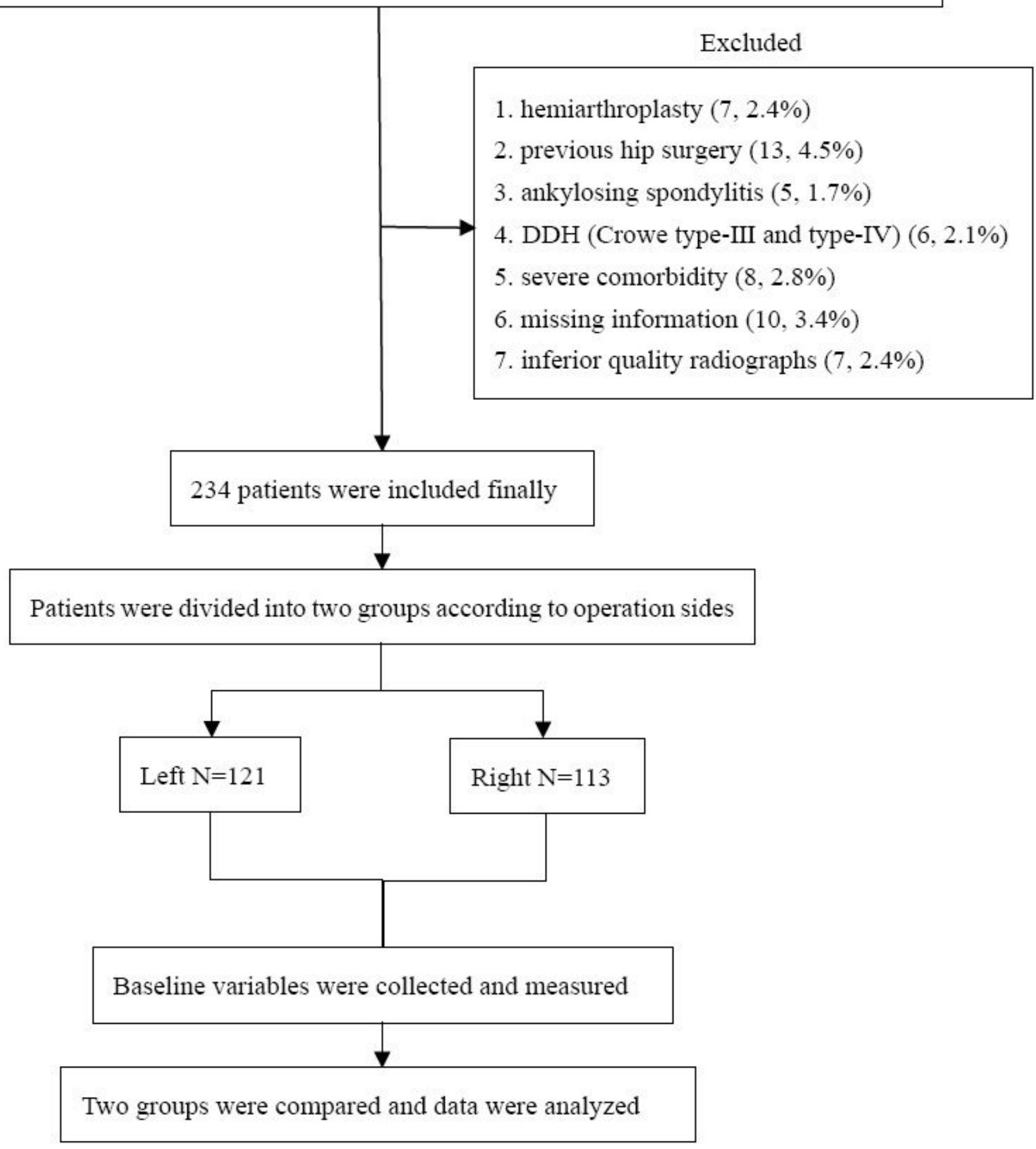

\section{Figure 1}

Flowchart that illustrates patient inclusion and exclusion. THA, total hip arthroplasty; DDH, developmental dysplasia of hip; N, number. 


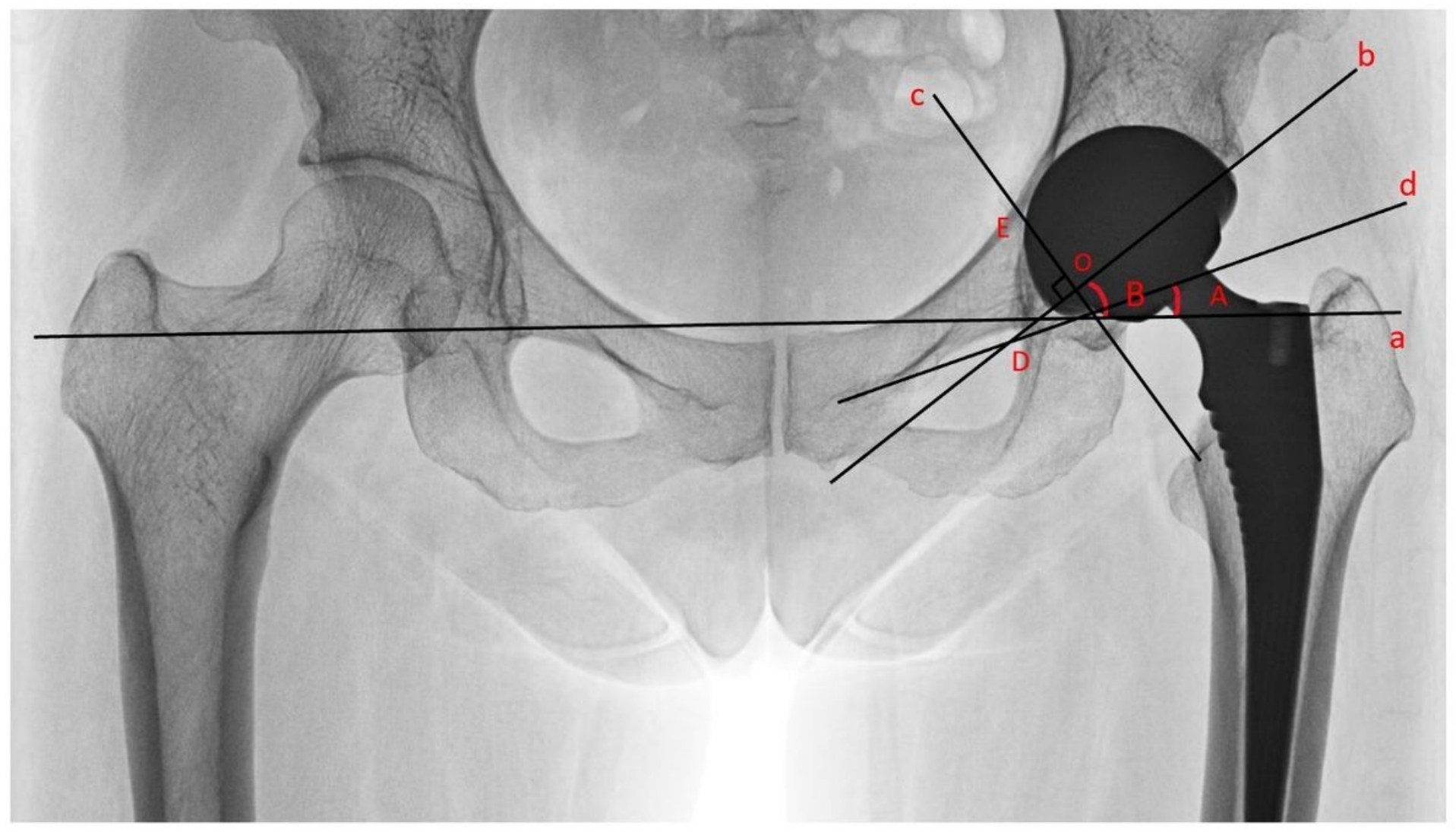

\section{Figure 2}

The plain radiograph in anterior-posterior position (AP) of hip after operation. a, the trans-teardrop line; $b$, the line of acetabular cup opening; $c$, the vertical of $b$ from the visible part of the femoral head; $O$, the intersection of $b$ and $c$; $E$, the intersection of $c$ and acetabular cup in the plain radiograph; $D, O E=O D$; $d$, the line between $D$ and the intersection of femoral and cup in the plain radiograph; $A$, the anteversion angle; $B$, the inclination angle. 


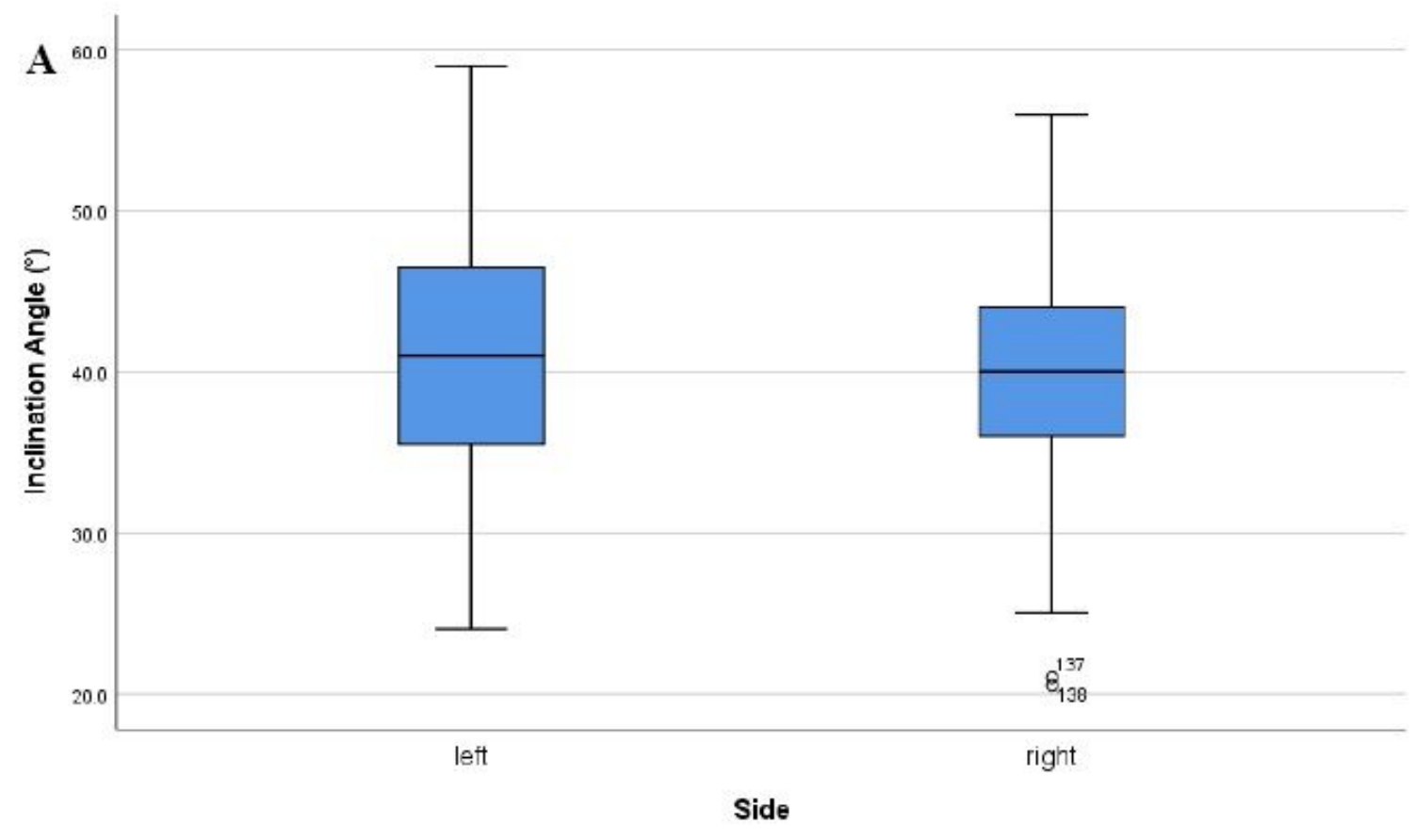

B

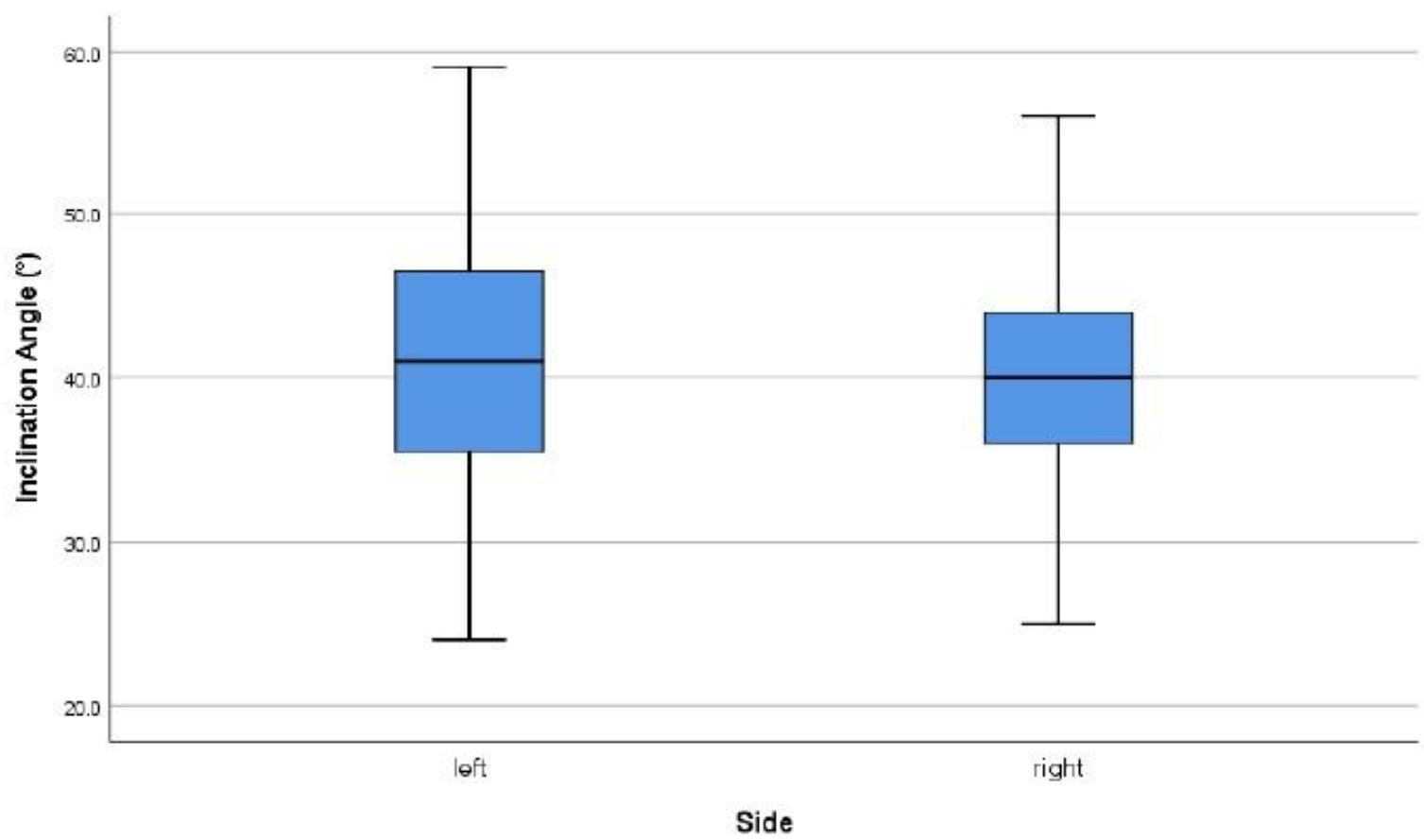

Figure 3

Box plot of inclination angle in both sides. (A) There are two outliers in the right side. (B) Remove the two outliers in the right side. No significant difference between A and B. 

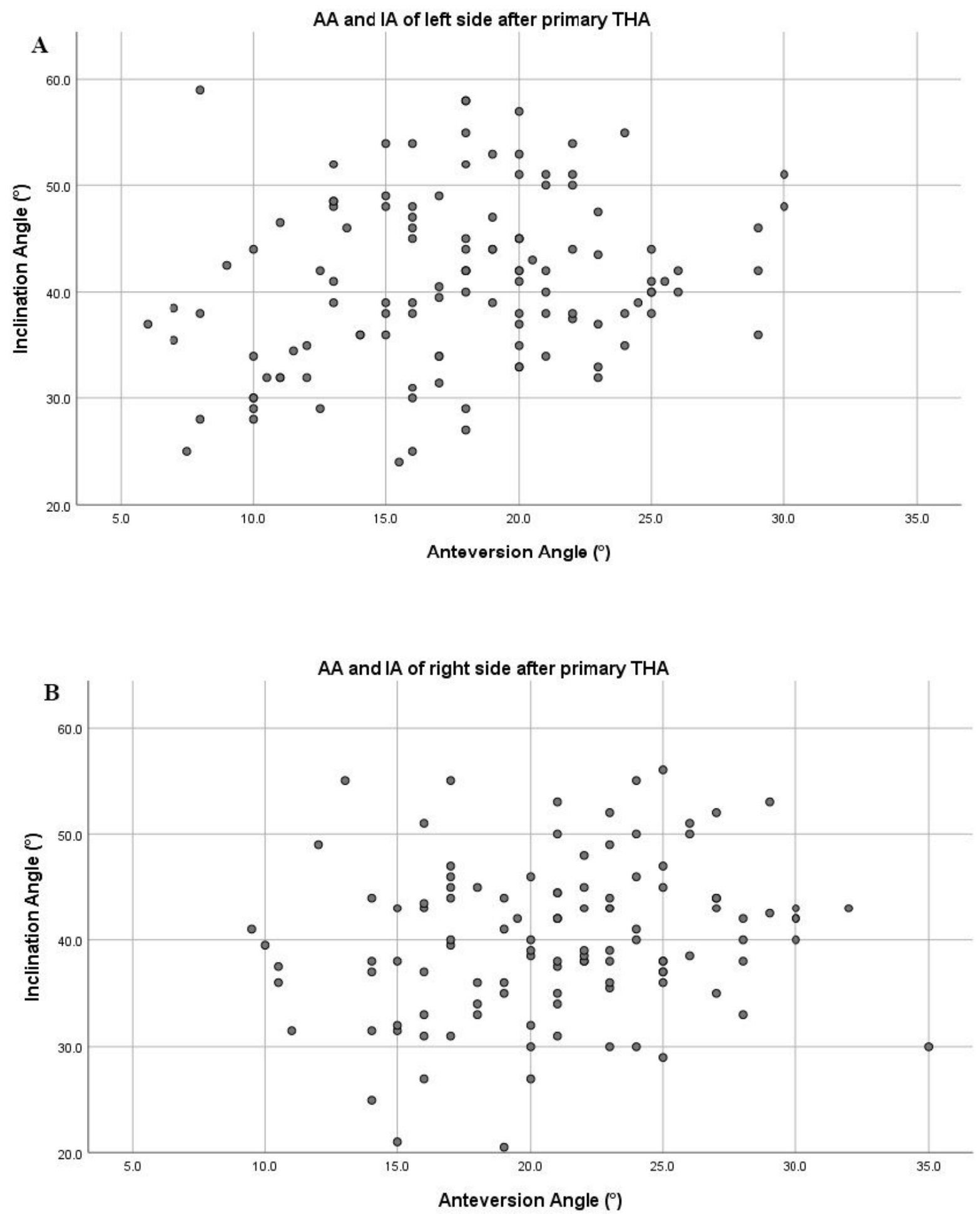

Figure 4

(A) Scatterplot of AA and IA of left side after primary THA. (B) Scatterplot of AA and IA of right side after primary THA. THA, total hip arthroplasty. 